Hidemori Shiraishi MD, Hajime Suzuki Mo PhD, Takahiro Suzuki MD, Norikazu Katsumata MD PhD, Setsuro Ogawa MD PhD

\title{
Fading responses in the evoked EMG after rocuronium in cats
}

This study was performed to evaluate the inhibitry effect on motor nerve terminals by rocuronium using recovery curves of muscle compound action potentials (CAPs) and train-of-four ratios (TOFRs) in anaesthetized cats, and to compare the results with other relaxants reported previousily. Recovery curves were derived from the amplitude of the CAP induced in the gastrocnemius muscle by the second of a paired stimulus (test response) to the sciatic nerve and compared with results evoked by the first component (conditioning response). The interval between the paired stimuli was increased stepwise from 7 to $1,000 \mathrm{msec}$, and the differences in amplitude of the test and conditioning responses were plouted on a graph by relating the changes in paired intervals. The recovery curve after rocuronium was less inhibited than after pancuronium, ( $100.4 \pm 5.9 \%, 82.3 \pm 6.7 \%$ and $68.5 \pm 6.7 \%$ at 60,100 and 500 msec intervals, compared with $70.3 \pm 3.3 \%, 59.0 \pm 4.7 \%$ and $46.7 \pm 4.3 \%$ afier pancuronium $(P<0.05)$. The recovery curves with d-tubocurarine were more depressed than with pancuromium; however, the $R C$ with vecuronium was similar to that of rocuronium. The degree of fade in TOF by rocuronium was also less than those seen with $d$ tubocurarine and pancuronium. The results obtained suggest that rocuronium has less inhibitory effect on motor nerve terminals than do d-tubocurarine and pancuronium, and has a similar effect to that of vecuronium.

Cette étude évalue l'effet inhibiteur du rocuronium sur les terminaisons nerveuses motrices en utilisant des courbes de récupération de potentiels d'action composés (CAP) et de

\section{Key words}

MEASURFMENT TECHNIQUES: electromyography;

NEUROMUSCULAR RELAXANTS: d-tubocurarine,

pancuronium, rocuronium, vecuronium; NEUROMUSCULAR TRANSMISSION.

From the Department of Anaesthesiology. Surugadai Nihon University Hospital, Tokyo.

Address correspondence to: Dr. Hajime Suzuki, Department of Anaesthesiology, Surugadai Nihon University Hospital. 1-8-13, Kanda-Surugadai, Chiyoda-ku, Tokyo, 101, Japan. Tel. 03-3293-1711, Fax. 03-3293-2600.

Accepted for publication 23rd August, 1992. rapports de train-de-quatre (TOF) chez des chats anesthésiés et compare ses résultats avec ceux d'autres relaxants déjà connus. Les courbes de récupération sont dérivées de l'amplitude de CAP provoqués dans le muscle gastrocnémien par le deuxième d'une paire de stimuli (test de réactivité) appliqués au nerf sciatique et comparé avec le résultat obtenu après la première excitation (réponse de conditionnement). L'intervalle entre le couple de stimuli a été augmenté par paliers de 7 à $1000 \mathrm{msec}$ et la différence d'amplitude du test de réactivité et de conditionnement est portée sur un graphique en relation avec les changements enregistrés par couple d'intervalles. La courbe de récupération du rocuronium est moins inhibée que ceile du pancuronium $(100,4 \pm 5,9 \%, 82,3 \pm 6,7$ et $68,5 \pm 6,7 \%$ à des intervalles de 60, 100, et 500 msec comparativement à $70,3 \pm$ $3,3 \%, 59,0 \pm 4,7 \%$ ef $46,7 \pm 4,3 \%$ après pancuronium : $P<$ $0,05)$. Les courbes de récupération sont encore plus abaissées avec la d-tubocurarine qu'avec le pancuronium, alors que celles du vécuronium sont identiques à celles du rocuronium. Le degré d'affaiblissement de la réponse du TOF par le rocuronium est aussi moindre que celui observé avec la d-tubocurarine et le pancuronium. Ces résultats suggèrent que le rocuronium a un effer inhibiteur moindre sur les terminaisons du neurone moteur que la d-rubocurarine et le pancuronium et un effet identique $\grave{a}$ celui du vécuronium.

Non-depolarizing or competitive neuromuscular block is characterized by a waning or fading response of the affected muscle to indirect repetitive stimulation. The second response of paired repeated stimuli show different responses such as potentiation or wane depending on the interval between the two stimuli. ${ }^{1-3}$ Paired stimuli have been applied to peripheral nerves in humans and in cats, and the amplitude of the compound action potentials (CAPs) evoked in the muscle by the second member of the stimulus pair (test response) has been compared with those evoked by the first (conditioning response). If the interyal between the two components (the pair interval) is increased stepwise from 7 to $1,000 \mathrm{msec}$, the differences in amplitude of the test and conditioning responses resulting from the changes in pair intervals produces a recovery curve (RC). ${ }^{11}$ It has been demonstrated that the recovery curve during partial block with nondepolating relaxants shows a characteristic pattern of slight potentiation at very 
short intervals of less than $20 \mathrm{msec}$ of stimuli, followed by considerable depression at longer intervals. The degree of the potentiation and depression differed with the different neuromuscular blocking drugs under similar levels of block. $^{1-3}$

The present study was undertaken to compare the RC during partial paralysis by rocuronium, a new steroidal relaxant, with results using other neuromuscular blockers in anaesthetized cats.

\section{Methods}

The study was approved by the Ethical Committee for Animal Investigation at Nihon University School of Medicine, and Surugadai Nihon University Hospital.

\section{Materials and preparation}

Ten cats of both sexes were anaesthetized with 15 to 25 $\mathrm{mg} \cdot \mathrm{kg}^{-1} \mathrm{ketamine} i \mathrm{~m}$ followed by intermittent administration of 5 to $10 \mathrm{mg} \cdot \mathrm{kg}^{-1}$ of pentobarital sodium iv. The lungs were ventilated with air using an animal respirator keeping the end-tidal carbon dioxide concentrations at $3.5 \%$ with an expired gas monitor. Cardiovascular variables were monitored by ECG and direct measurement of BP from the carotid artery and recorded (Recti-Horiz$8 \mathrm{~K} 21-\mathrm{L6}^{\circ}$ ). The oesophageal temperature was maintained at $38^{\circ} \mathrm{C}$ with a heating mattress. The cat's lumbar spinal processes and unilateral calcaneus were immobilized. The jpsilateral sciatic nerve was severed, and its peripheral part was isolated from the surrounding tissue and attached to two stimulating electrodes. Another two electrodes to measure CAPs were fixed on the fascia covering the gastrocnemius muscle. These electrodes and exposed tissues were maintained in a paraffin pool at $38^{\circ} \mathrm{C}$.

A rectangular pulse using supramaximal strength and a duration of $0.2 \mathrm{msec}$ was applied every ten seconds ( 0.1 $\mathrm{Hz}$ ). Compound action potentials were induced and recorded using a module type EMG instrument (Medelec MS6 ${ }^{\oplus}$ ) with the time constant during 0.16 to $16 \mathrm{kHz}$. The amplitude of CAPs prior to administration of rocuronium (control) showed $13.4 \pm 1.4 \mathrm{mV}$ (mean $\pm \mathrm{SD}$ ), and the CAPs during partial block were amplified to nearly control levels.

\section{Stimulation patterns}

Single shock stimulation at $0.1 \mathrm{~Hz}$ was applied serially during the experiments, and the amplitude of CAP to the stimulation before rocuronium was used as the control. Paired pulses at each interval followed by train-of-four (TOF) pulses were applied with a pause of ten seconds after the last stimulation in the train to obtain control patterns of RC and TOFR. After the control values were obtained, neuromuscular block by rocuronium was verified by a single pulse at $0.1 \mathrm{~Hz}$. When the amplitude of CAP by single stimuli recovered from complete block to $10 \%$, $25 \%, 75 \%$ and $100 \%$, the same stimulation patterns to obtain RC and TOFR were performed.

\section{Variables}

\section{AMPLITUDE OF CAPS}

The amplitudes of the CAPs from single shock stimulation at $0.1 \mathrm{~Hz}$ were compared before and after administration of the test agent and were expressed as percentage of control.

\section{Recovery curve (RC) of CAPs}

The original method of obtaining $\mathrm{RC}$ has been reported previously.' A pair of pulses was applied to the sciatic nerve with a ten-second pause. The first stimulus of the pair was termed the "conditioning stimulus" and the second the "test stimulus." The ratio of the amplitude of the muscle CAP (M2) evoked by the test stimulus to that (M1) of the conditioning stimulus was obtained. The interval between paired stimuli ranged from 7 to 1,000 msec. Recordings of the paired responses were made every millisecond and between 7 and $10 \mathrm{msec}$, every $20 \mathrm{msec}$ between 10 and $100 \mathrm{msec}$, and every $500 \mathrm{msec}$ between 100 and $1,000 \mathrm{msec}$, respectively. When each M2/Ml ratio was plotted against the interval between the paired stimuli, a curve, i.e., a recovery curve ( $R C$ ), for the muscle CAP could be obtained. The recording at each paired interval was accomplished with one measurement, because it had been shown previously that a constant ratio was obtained by preliminary measurements repeated in the same paired interval. ${ }^{1-3}$ We then measured the responses to a series of paired stimuli to obtain a RC of approximately $120 \mathrm{sec}$.

\section{Train-of-four ratio (TOFR) of CAPS}

We then applied a train-of-four stimulation at $2 \mathrm{~Hz}$ to obtain the ratio (TOFR) of the amplitude of the fourth response (M4) to the amplitude of the first response (M1) expressed as a percentage.

\section{Administration of rocuronium}

After control variables had been obtained, $0.35 \mathrm{mg} \cdot \mathrm{kg}^{-1}$ of rocuronium was administered $i v$. If complete neuromuscular block was not obtained, cumulative doses from 0.15 to $0.35 \mathrm{mg} \cdot \mathrm{kg}^{-1}$ were applied until the twitch response was abolished. Twitch responses from single stimuli with a frequency of $0.1 \mathrm{~Hz}$ were obtained during the experiments to estimate the level of neuromuscular blockade. Recovery curves and TOFRs of CAPs were recorded as described above. 


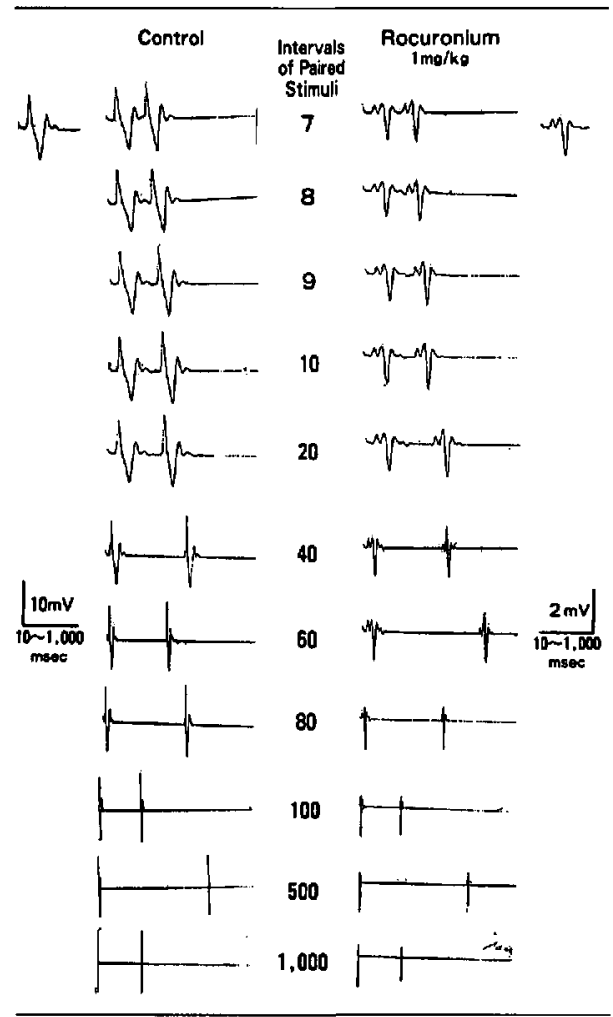

FIGURE 1 An example of the serial tracing of single and paired CAPs at various stimulation intervals. The left series are controls in which a CAP from a single pulse stimulation is demonstrated by action potentials from several muscle fibres. It has a first positive peak followed by a large negative peak, and followed by two small positive potentials. The largest positive to negative peak is estimated as the amplitude of the CAP. The second CAPs (test responses) in each paired response show slightly larger amplitudes than those seen with the first CAP (conditioning response) in $100 \mathrm{msec}$ and shorter intervals of stimulation. The right series are CAPs which were depressed to almost $10 \%$ of the control amplitudes by rocuronium. The first positive peak in the Figure of CAP of control is split into two small positive peaks, but the second positive reflection is estimated as the measureable positive peak.

\section{Evaluation of results}

The results at each time during recovery period from neuromuscular block were compared with control values. Comparisons were also made with results obtained from similar previous studies with other neuromuscular blockers. ${ }^{3}$ All data were expressed as mean \pm SEM.

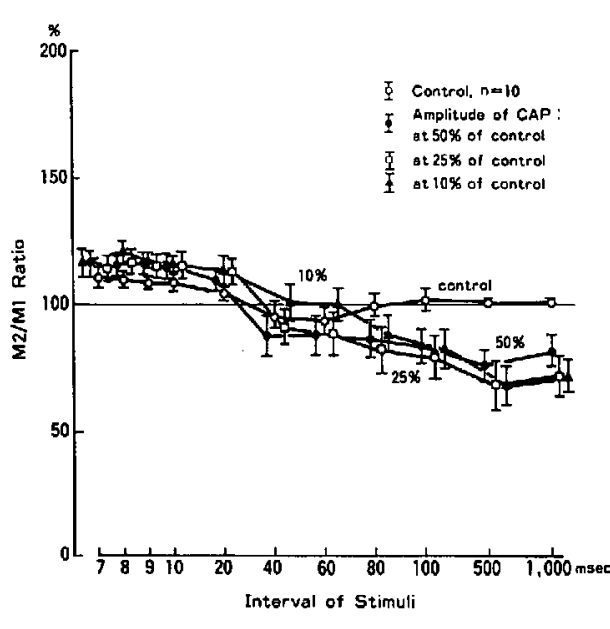

FIGURE 2 Recovery curves of muscle CAPs at control and at three levels of neuromuscular block by rocuronium.

Comparisons within experimental protocols were made using a repeated measurement analysis of variance (ANOVA). Multiple comparisons between individual means were performed using Newmann-Keuls method. Differences with $P<0.05$ were considered significant.

\section{Results}

\section{Recovery curves of CAPs}

An example of single and paired CAPs at various stimulation intervals is given in Figure 1. It shows a control series (left) and a series obtained during partial block with rocuronium (right) in a cat. The amplitudes of M2 in the control were very slightly potentiated compared to the amplitude of $\mathrm{M} 1$ at intervals shorter than $20 \mathrm{msec}$, and they were almost equal to that of M1 at longer intervals. When the amplitude of the single CAP was inhibited to almost $10 \%$ of control levels as shown in the right series of Figure 1, slight potentiation of the amplitudes of $M 2$ compared to those of Ml was found at intervals shorter than $60 \mathrm{msec}$, and subsequent depression of the amplitudes of $\mathrm{M} 2$ compared to those of $\mathrm{M} 1$ were observed at longer intervals of paired stimuli.

Similar changes in the amplitudes of M2 in response to a range of intervals of paired stimuli were noted in each cat. Data for recovery curves from the mean ratios of $\mathrm{M} 2 / \mathrm{M} 1$ at various time intervals of paired stimuli are presented in Figure 2, showing three RCs at different 


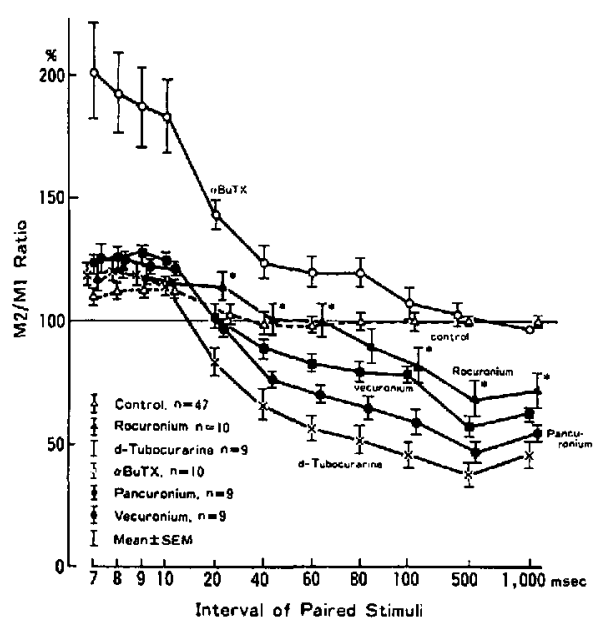

FIGURE 3 Recovery curve obtained from the mean ratios ( \pm SEM) of $\mathrm{M} 2 / \mathrm{Ml}$ when the amplitude of the CAP was inhibited to nearly $10 \%$ of control levels by rocuronium is compared with RCs obtained at similar levels of inhibition by the other relaxants evaluated (Reprinted by permission from Katsumata $\mathrm{N}$ et al. ) $^{3}$

levels of neuromuscular block with rocuronium demonstrating similar patterns and equal levels of changes in every RC.

In Figure 3, a RC obtained from the mean ratios of $\mathrm{M} 2 / \mathrm{M} 1$ when the amplitude of the CAP was inhibited to almost $10 \%$ of control by rocuronium is presented in comparison with $\mathrm{RCs}$ which were obtained during similar levels of inhibition by d-tubocurarine, pancuronium, vecuronium, and $\alpha$-bungarotoxin. ${ }^{3}$

The pattern of the RCs resembled that for other nondepolarizing relaxants. Higher levels of $\mathbf{R C}$ were found after rocuronium at $20 \mathrm{msec}$ and at longer intervals of the paired stimuli than with those of other non-depolarizing relaxants. For example, the M2/M1 ratios of $100.4 \pm$ $5.9 \%, 82.3 \pm 6.7 \%$ and $68.5 \pm 6.7 \%$ at 60,100 and 500 msec intervals after rocuronium differed from $70.3 \pm$ $3.3 \%, 59.0 \pm 4.7 \%$ and $46.7 \pm 4.3 \%$ at the equivalent intervals after pancuronium $(P<0.05)$. The recovery curves with d-tubocurarine were more depressed than with pancuronium and the $\mathrm{RC}$ with vecuronium was similar to that of rocuronium. The pattern of $\mathrm{RC}$ with rocuronium was different from that of $\alpha$-bungarotoxin ( $\alpha$-BuTx)

\section{Train-of-four ratios}

Mean train-of-four ratios at several inhibited amplitudes of CAPs by several neuromuscular blocking agents ${ }^{3}$ are

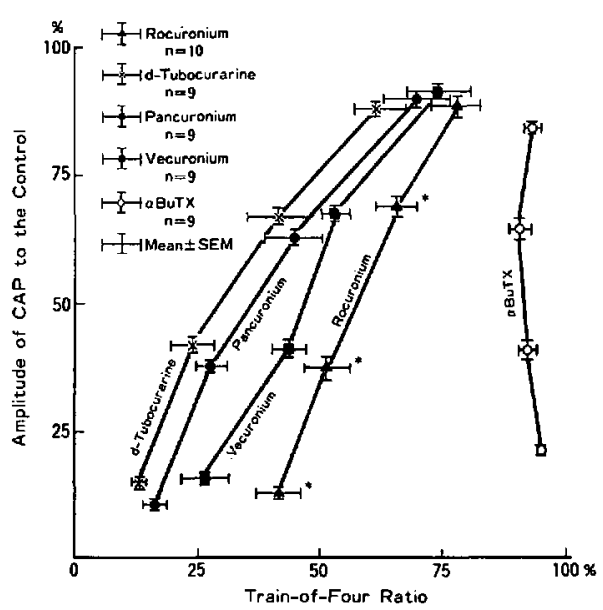

FIGURE 4 Mean train-of-four ratios at four levels of neuromuscular block by rocuronium compared with those by other relaxants (Reprinted by permission from Katsumata $\mathrm{N}$ et al.). ${ }^{3}$

*Different from pancuronium and d-tubocurarine $(P<0.01)$.

shown in Figure 4. The degree of fade in the train-of-four (TOF) with rocuronium was less than with d-tubocurarine and pancuronium $(P<0.01)$ at similar levels of block. The fade was not significantly different from that for vecuronium. There was no fade produced by $\alpha$-BuTX.

\section{Discussion}

The present experiments confirmed that rocuronium blocked neuromuscular transmission with a non-depolarizing pattern ${ }^{1-3}$ in the RC of CAPs induced from the gastrocnemius muscle in cats. However, the depressed RCs during partial block by rocuronium were less than those produced by d-tubocurarine and pancuronium, and were similar to those of vecuronium. The degree of fade in TOF with rocuronium co-responded with the depression of the $\mathrm{RCs}$ in a similar fashion to, but less than with, d-tubocurarine and pancuronium. This suggests that rocuronium may have less inhibitory effect on the motor nerve terminals than the other relaxants evaluated.

Using rat diaphragm-phrenic nerve preparations treated with d-tubocurarine or magnesium, Hubbard and Schmidt and Hubbard ${ }^{5}$ studied the fluctuation of endplate potential (epp) amplitudes by the second impulse (testing volley) and miniature endplate potential (mepp) frequency after a stimulus (conditioning volley) of paired stimuli at various intervals. They concluded that, when measured as epps and mepp for a $100-200$ msec period, a single nerve 
impulse increased acetylcholine $(\mathrm{ACh})$ release which was followed by a decrease. Wilson ${ }^{6,7}$ demonstrated that this increased release resulted from mobilization of $\mathrm{ACh}$ with the residual calcium ion which had been induced by the depolarization process at the nerve terminal by the conditioning impulse, and that the mobilization decreased with time.

According to Waud and Waud ${ }^{8,9}$ and our previous report ${ }^{1}$ of partial curariform block, the threshold fibres which have a reduction in available receptors is reflected by the amount of released transmitter. Thus the size of the summated muscle action potential in the partially curarized state is related to the total number of muscle fibres that have reached a potential threshold in the whole muscle.

When paired stimuli are applied to nerves innervating partially curarized muscle in humans and animals, it is assumed that the amplitude of the compound muscle action potential (CAP) by the second stimulus (test response) is influenced by the relative changes of the amount of released transmitter in response to the first stimulus (conditioning response) and is dependent on the interval between the paired stimuli.

Suzuki et al. ${ }^{1}$ found in anaesthetized patients that the $\mathrm{RC}$ of muscle CAPs following gallamine and d-tubocurarine showed an identical time course of mobilization process of transmitter from nerve terminals after the conditioning stimulus in studies with rats by Hubbard $e t$ $a l^{4,5}$ A similar pattern in the RCs of CAPs had been demonstrated by Katsumata et $a l^{3}$ during partial block with conventional non-depolarizing relaxants in cats. In contrast, the pattern of RCs produced by lignocaine was found to be characterized by marked and serial depression of response to test stimuli at all intervals between paired stimuli, ${ }^{2}$ and the pattern of RCs produced by $\alpha$-BuTX was characterized by profound potentiation of the responses to test stimuli at shorter intervals between paired stimuli, followed by a gradual recovery. ${ }^{3}$ They suggested that the RC produced by $\alpha$-BuTX may demonstrate the physiological time course of the mobilization process of transmitter after a conditioning stimulus, because it is believed that $\alpha$-BuTX affects only acetylcholine receptors at the endplate, and does not affect prejunctional receptors. ${ }^{10-12}$ Further, they ${ }^{3}$ demonstrated that non-depolarizing relaxants showed marked differences in depression at intervals longer than $40 \mathrm{msec}$ during profound neuromuscular blockade. The depression was most prominent with dtubocurarine, followed by pancuronium and vecuronium. Also, fade of TOF followed a similar difference with each neuro-muscular relaxant. ${ }^{3}$ The authors concluded that depression of RCs and fade of TOF by non-depolarizing relaxants may be caused by an inhibitory effect at the motor nerve terminals as many investigators have reported. ${ }^{13-17}$
The results of this study demonstrate that rocuronium has an inhibitory effect on motor nerve terminals, although the effect is less than that produced by d-tubocurarine and pancuronium.

In studies on differences of fade in TOF among nondepolarizing relaxants in clinical cases, several investigators $^{18-20}$ have found that d-tubocurarine caused a more pronounced fade than did pancuronium or vecuronium. Gibson et al. ${ }^{20}$ noted that pancuronium caused a greater fade than vecuronium which is similar to our results, although Storella et $a{ }^{21}{ }^{21}$ reported that such differences among relaxants could not be observed when they were examined at steady-state block in isolated phrenic nervediaphragm preparations of the mouse.

Based on clinical studies involving mechanical twitch responses of the thenar muscle to rocuronium, identical levels of TOF fade with vecuronium were found by Mark et $a .^{22}$ and Foldes et al..$^{23}$ Our results did not demonstrate any difference in TOF fade or RC depression between the two relaxants.

It has not yet been determined whether these effects on the RCs of CAPs and levels of fade in TOF influence the clinical mode of action of the relaxants or not. However, it should be borne in mind that the fade in TOF as a monitor of neuromuscular blockade may be expressed more weakly by rocuronium and vecuronium than by d-tubocurarine and pancuronium at similar levels of blockade.

\section{Acknowledgements}

The authors are grateful to Teruko Ohta, V.D. for her technical assistance and cooperation.

\section{References}

1 Suzuki H, Kanayama $T$, Nakagawa $H$, Yazaki S. An electromyographic study of muscle relaxants in man. $\mathrm{Br} \mathrm{J}$ Anaesth $1975 ; 47$ : 592-9.

2 Suzuki H, Yazaki S, Kanayama T, et al. Neuromuscular effects of i.a. infusion of lignocaine in man. $\mathrm{Br} \mathrm{J}$ Anaesth 1977; 49: 1117-22.

3 Katsumata N, Shiraishi H, Itagaki T, Tai, K, Suzuki, $H$. Study of neuromuscular transmission with evoked electromyography -10 . Comparison of the responses during partial blockade by $\alpha$-bungarotoxin and non-depolarizing relaxants. MASUI (English Abstract) 1990; 39: 1178-87.

4 Hubbard JI, Schmidt RF. An electrophysiological investigation of mammalian motor nerve terminals. J Physiol $1963 ; 166: 145-67$.

5 Hubbard $J$. Repetitive stimulation at the mammalian neuromuscular junction and the mobilization of transmitter. J Physiol 1963; 169; 641-62.

6 Wilson DF. Facilitation of transmitter release at the mam- 
malian neuromuscular junction. Am J Physiol 1974; 227 ; 1098-102.

7 Wilson $D F$. Influence of presynaptic receptors on neuromuscular transmission in rat. Am J Physiol 1982; 242: C366-C72.

8 Waud BE, Waud DR. The relation between tetanic fade and receptor occlusion in the presence of competitive neuromuscular block. Anesthesiology 1971; 35: 456-64.

9 Waud $D R$, Waud BE. In vitro measurement of margin of safety of neuromuscular transmission. Am J Physiol 1975; 229: $1632-4$.

10 Lee CY. Chemistry and pharmacology of polypeptide toxins in snake venoms. Ann Rev Pharmacol 1972; 12: 265-86.

11 Lee C, Chen D, Katz RL. Characteristics of nondepolarizing neuromuscular block: (1) post-junctional block by alpha-bungarotoxin. Can Anaesth Soc J 1977; 24: 212-9.

12 Jones SW, Salpeter MM. Absence of $\left[{ }^{125} I\right] \mathbf{\alpha}$-bungarotoxin binding to motor nerve terminals of frog, lizard and mouse muscle. J Neurosci 1983; 3: 326-31.

13 Bowman $W C, W e b b S N$. Tetanic fade during partial transmission failure produced by non-depolarizing neuromusclar blocking drugs in the cat. Clinic Exper Pharmacol Physiol 1976; 3: 545-55.

14 Wilson DF. Depression, facilitation, and mobilization of transmitter at the rat diaphragm neuromuscular junction. Am J Physiol 1979; 237: C31-C7.

15 Bowman WC. Prejunctional and post junctional cholinoceptors at the neuromuscular junction. Anesth Analg 1980; 59: $935-43$.

16 Gibb AJ, Marshall IG. Pre- and post-junctional effects of d-tubocurarine and other nicotinic antagonists during repetitive stimulation in the rat. J Physiol 1984; 351: 275-97.

17 Matzner H, Parnas H, Parnas I. Presynaptic effects dtubocurarine on neurotransmitter release at the neuromuscular junction of the frog. J Physiol 1988; 398: 109-21.

18 Stanec A, Baker T. Prejunctional and postjunctional effects of tubocurarine and pancuronium in man. $\mathrm{Br} J$ Anaesth 1984; 56: 607-11.

19 Cashman $J N$, Jones RM, Vella LM. Fade characteristics and onset times following administration of pancuronium, tubocurarine and a mixture of both agents. $\mathrm{Br} \mathrm{J}$ Anaesth $1985 ; 57: 488-92$.

20 Gibson FM, Mirakhur $R K$. Train-of-four fade during onset of neuromuscular block with nondepolarising neuromuscular blocking agents. Acta Anaesthesiol Scand 1989; 33: 204-6.

21 Storella RJ, Slomowitz SA, Rosenberg $H$. Relationships between block-of-twitch and train-of-four fade in the mouse phrenic nerve-diaphragm preparation. Can J Anaesth 1991; 38: 401-7.
22 Wierda JM, Kleef UW, Lambalk LM, Kloppenburg WD, Agoston $S$. The pharmacodynamics and pharmacokinetics of Org 9426, a new nondepolarizing neuromuscular blocking agent, in patients anaesthetized with nitrous oxide, halothane and fentanyl. Can J Anaesth 1991; 38: 430-5.

23 Foides FF, Nagashima $H$, Nguyen HD, Schiller WS, Mason MM. The neuromuscular effects of ORG 9426 in patients receiving balanced anaesthesia. Anesthesiology 1991; 75: 191-6. 